\title{
Genetic Improvement of Mastitis Resistance: Validation of Somatic Cell Score and Clinical Mastitis as Selection Criteria
}

\author{
J. Ødegård, G. Klemetsdal, and B. Heringstad \\ Department of Animal Science, Agricultural University of Norway, \\ P.O. Box 5025, N-1432 Ås, Norway
}

mastitis (CM) records, or by indirect selection using traits genetically correlated to mastitis, e.g., SCC in milk; a measure of the inflammatory response in the udder. The level of SCC increases rapidly during infection, and SCC can therefore be used as an indicator of mastitis. During infection, SCC contains more than 95\% polymorphonuclear neutrophils, playing an important role in the defense of the mammary gland, and SCC is thus not only an indicator for mastitis, but is also a measure for amount of the cells necessary to combat the infection (Detilleux et al., 1997). At the time of initial infection, the number of macrophages present may also be critical for the outcome of the infection (Schukken et al., 1997). Selection for lowest possible SCC may therefore reduce the cows' ability to respond to infection, and some optimum SCC may be desirable. If so, a nonlinear genetic relationship between $\mathrm{CM}$ and SCC, at lower SCC values, is to be expected. Schukken et al. (1994, 1999), Shuster et al. (1996), and Suriyasathaporn et al. (2000) found that low initial SCC values were associated with higher risk, or severity of subsequent infection. Contrary to this, Coffey et al. (1986), Beaudeau et al. (1998), and Rupp and Boichard (2000) found no indication that cows with initially low SCC were at greater risk of subsequent mastitis. In the latter two studies, clinical cases with no previous SCC measurement were excluded from the analyses, leading to selected data, which may partly explain the absence of increased risk at very low levels of SCC (Beaudeau et al., 2001).

In the Nordic countries selection for improved mastitis resistance is mainly based on CM records (Heringstad et al., 2000), while in other countries genetic improvement of udder health mainly relies on selection for reduced SCC (summarized by International Bull Evaluation Service, 1996), and possibly other traits such as udder type traits and longevity. Hence, there is need for increased knowledge about the genetic relationship between SCC and mastitis. Selection for reduced SCC, as well as CM, may result in genetic change of incidences of both clinical and subclinical mastitis. However, the possible indirect effect on the incidence of subclinical mastitis is difficult to study due to lack of data for subclinical mastitis. Therefore, the effect of

Received January 12, 2003.

Accepted April 9, 2003.

Corresponding author: J. Ødegård; e-mail: jorgen.odegard@ihf. nlh.no. 
Table 1.. Summary statistics of datasets used for prediction of transmitting abilities of clinical mastitis (CM) and lactation mean SCS (LSCS), calculated from first-crop daughters, utilizing complete and smaller ${ }^{1}$ size of progeny groups, respectively. Mean and standard deviation of PTA for the two traits are also included.

\begin{tabular}{lcc}
\hline & Complete daughter groups & Smaller daughter groups \\
\hline Number of records & 495,681 & 250,290 \\
Number of sires & 2043 & 2043 \\
Number of herd-year classes & 238,843 & 120,990 \\
Mean number of records per herd-year class & 2.08 & 2.07 \\
Mean number of daughters per sire & 243 & 123 \\
Mastitis frequency $(\%)^{2}$ & 15 & 15 \\
Mean (SD) LSCS & $4.12(0.98)$ & $4.12(0.98)$ \\
Calving year & $1978-1995$ & $1978-1995$ \\
Mean (SD) PTAs for CM CM $^{4}$ & $-0.0005(0.02)$ & $-0.0002(0.02)$ \\
Mean (SD) PTAs for LSCS & $0.0020(0.13)$ & $0.0084(0.12)$ \\
\hline
\end{tabular}

\footnotetext{
${ }^{1}$ The dataset with smaller daughter groups was created by randomly excluding approximately $50 \%$ of the herds.

${ }^{2}$ Mastitis frequency $=$ percentage of cows with at least one record of veterinary treatment of CM in a period from $15 \mathrm{~d}$ before to $120 \mathrm{~d}$ after first calving.

${ }^{3} L S C S_{i}=\frac{1}{n_{i}} \sum_{j=1}^{n_{\mathrm{i}}} S C S_{i j}$, where $n_{i}$ is number of records for cow $i$.

${ }^{4}$ Grandaughters did not contribute to the sires' PTA.
}

selection on incidence of $\mathrm{CM}$ relative to $\mathrm{SCC}$ can be compared by the relative changes in incidence of $\mathrm{CM}$ only. In Norway, records of both SCC and CM are available from 1978 onwards, and CM has been included in the total merit index used for selection of sires in Norwegian Cattle (NRF) since 1978 (Heringstad et al., 2000). Therefore, the Norwegian data have great potential for studies of the genetic relationship between SCC and CM.

The objectives of this study were to use the Norwegian data to compare the relative efficiency of direct selection for increased mastitis resistance, using CM records, versus indirect selection, using SCC, to study whether efficiency can be improved by combining information on CM and SCC, and to examine the data for a possible nonlinear genetic relationship between the two traits.

A comparison of direct versus indirect selection can be carried out by use of selection index theory and expected additive genetic response. This method requires known genetic correlation between the traits. Alternatively, one can compare the relative efficiency of selecting on CM or on lactation mean SCS (LSCS), by regressing incidence of CM in second-crop daughters on PTA from univariate genetic analyses of both traits based on firstcrop daughters. The regressions require no assumptions on the genetic correlation between traits. Efficiency of selection is here defined as the ability of the PTA to predict incidence of CM in future daughters.

\section{MATERIALS AND METHODS}

\section{Prediction of Transmitting Abilities}

Records of SCC were extracted from a dataset described by Ødegård et al. (2003). A total of 495,681 first-crop daughters in first lactation from NRF sires evaluated in the period from 1978 to 1995 were used in the study. Records were included if age at first calving was in the interval 450 to $1200 \mathrm{~d}$, and lactation started with normal calving. Records were restricted to those with SCC values between 5000 and $6,400,000$ cells $/ \mathrm{ml}$, in the period 6 to 305 DIM. Records of SCS, defined as the natural logarithm of $(\mathrm{SCC} / \mathrm{ml}) * 10^{-3}$, were averaged per daughter as LSCS. Records of CM were available from a dataset described by Heringstad et al. (1999, 2001), where mastitis was defined as a binary trait based on whether or not the cow had at least one recorded treatment of $\mathrm{CM}$ in the period from $15 \mathrm{~d}$ before calving to $120 \mathrm{~d}$ after first calving. Cows born more than $5 \mathrm{yr}$ after their respective sires were assigned as second-crop daughters, otherwise they were considered first crop. Only cows with records of both LSCS and $\mathrm{CM}$ were used in calculation of PTA.

In the Norwegian data, the number of first-crop daughters per sire is large. To examine whether a smaller number of progeny would affect the results, a new dataset was created by randomly excluding approximately half of the herds. The resulting dataset had 250,290 records of first-crop daughters, and average number of first-crop daughters per sire was reduced from 243 to 123 . Descriptive statistics of both the complete and smaller dataset are given in Table 1.

As one of the aims of this study was to compare the relative efficiency of selecting on CM vs. LSCS, PTA used in the analyses should be based on information available at the time of selection. To avoid relatives such as grandaughters in contributing to the PTA, sires were separated into three groups; sires born before September 14, 1979, sires born in the period from Septem- 
ber 14, 1979, to August 31, 1985, and sires born after August 31, 1985. Accordingly, the daughters of these sires were split into three datasets, and prediction of transmitting abilities for each sire group was based on the corresponding and preceding dataset(s).

Another aim of the study was to examine the data for a possible nonlinear genetic relationship between the two traits. In such analyses, transmitting abilities should be predicted with the highest possible accuracy. Hence, PTA used in this analysis were based on all first-crop daughters.

For all datasets the following univariate linear sire model was used to predict transmitting abilities:

$$
\mathrm{Y}_{\mathrm{ijklm}}=\mathrm{A}_{\mathrm{i}}+\mathrm{M}_{\mathrm{j}}+\mathrm{HY}_{\mathrm{k}}+\mathrm{S}_{\mathrm{l}}+\mathrm{e}_{\mathrm{ijklm}}
$$

where

$$
\begin{aligned}
\mathrm{Y}_{\mathrm{ijklm}}= & \text { observation of clinical mastitis }(0=\text { healthy, } 1 \\
& =\text { diseased }) \text { or LSCS, for daughter } m \text { of sire } l, \\
& \text { calving at age } i, \text { in month } j \text { and herd-year class } \\
& k ; \\
\mathrm{A}_{\mathrm{i}}= & \text { fixed effect of age } i \text { at first calving, in } 15 \text { classes, } \\
& \text { where }<20 \text { mo is the first class, }>32 \text { mo the } \\
& \text { last class, and the other classes are in single } \\
& \text { months; } \\
\mathrm{M}_{\mathrm{j}}= & \text { fixed effect of month } j \text { of first calving, in } 12 \\
& \text { classes; } \\
\mathrm{HY}_{\mathrm{k}}= & \text { fixed effect of herd-year class } k ; \\
\mathrm{S}_{\mathrm{l}}= & \text { random effect of sire } l ; \text { and } \\
\mathrm{e}_{\mathrm{ijklm}}= & \text { random error term. }
\end{aligned}
$$

The pedigree file used in the analyses was that described by Heringstad et al. (1999), containing 2159 sires, of which 2043 sires had first-crop daughters with data.

The program PEST was used for prediction of transmitting abilities (Groeneveld and Kovac, 1990). Variance components for CM and LSCS, estimated by Heringstad et al. (1999) and Ødegård et al. (2003), respectively, were used as input parameters in the analyses. The variance components for sire and residual effects were 0.00115 and 0.12314 for CM, and 0.02324 and 0.85573 for LSCS, corresponding to heritabilities of 0.04 and 0.11 , respectively.

\section{Mean Daughter Deviation of Clinical Mastitis}

Mean daughter deviations (DYD) of CM were calculated on basis of a total of 684,897 second-crop daughters, from 321 elite sires, defined as those having more than 300 second-crop daughters. To obtain DYD, CM observations were deviated from solutions of fixed effects, as estimated by Heringstad et al. (2001), and averaged per sire. Observations from herd-year classes with one single observation were discarded.

\section{Relative Efficiency of LSCS and $\mathrm{CM}$ as Selection Criteria}

From selection index theory, the expected genetic response from sires to offspring in incidence of $\mathrm{CM}\left(\mathrm{R}_{\mathrm{CM}}\right)$ due to selection on either CM or LSCS, can be written:

$$
R_{C M}=i b_{C M, P T A_{j}} \sigma_{P T A_{j}}
$$

where

$i=$ intensity of selection for sires;

$b_{C M, P T A_{j}}=$ regression coefficient for incidence of clinical mastitis among second-crop daughters regressed on sires' PTA in first-crop daughters for trait $j, j=1,2$; and

$\sigma_{P T A_{\mathrm{j}}}=$ standard deviation of sires' PTAs for trait $j$.

$R_{C M}$ from [1] can be estimated as;

where

$$
\hat{R}_{C M}=i \hat{b}_{D Y D, P T A_{\mathrm{j}}} \hat{\sigma}_{P T A_{\mathrm{j}}}
$$

$\hat{b}_{D Y D, P T A_{\mathrm{j}}}=$ estimated weighted regression coefficient of mean daughter deviations for clinical mastitis among second-crop daughters on sires' PTA in first-crop daughters for trait $j$; and the other variables are as declared in [1].

In all regression analyses number of second-crop daughters per bull was used as weight.

For CM, the regression coefficient of DYD on predicted values is expected to be 1 for unbiased evaluation models. For comparison purposes, CM vs. LSCS, estimation of standardized regression coefficients was more appropriate to account for different variances of PTA for the two predictors. The estimated standardized weighted regression coefficient can also be written:

$$
\hat{b}_{{\text {SDYD }, S P T A_{j}}_{j}}=\hat{b}_{D Y D, P T A_{j}} \sqrt{\frac{\sum_{i=1}^{p}\left(w_{i}\left(P T A_{i j}-\overline{P T A}\right)^{2}\right)}{\sum_{i=1}^{p}\left(w_{i}\left(D Y D_{i}-\overline{D Y D}\right)^{2}\right)}}
$$

$$
\begin{gathered}
=\frac{\sum_{i=1}^{p}\left(w_{i}\left(D Y D_{i}-\overline{D Y D}\right)\left(P T A_{i j}-\overline{P T A_{i}}\right)\right)}{\sqrt{\sum_{i=1}^{p}\left(w_{i}\left(D Y D_{i}-\overline{D Y D}\right)^{2}\right) \sum_{i=1}^{p}\left(w_{i}\left(P T A_{i j}-\overline{P T A}\right)^{2}\right)}} \\
=\hat{r}_{D Y D, P T A_{j}}
\end{gathered}
$$


where

$\hat{b}_{S D Y D, S P T A_{\mathrm{j}}}=$ estimated standardized weighted regression coefficient of mean daughter deviations for clinical mastitis among secondcrop daughters on sires' predicted transmitting abilities in first-crop daughters for trait $j$;

$w_{i}=$ weight for sire $i$ (number of second-crop daughters), $i=1,2, \ldots ., p$;

$D Y D_{i}=$ DYD of clinical mastitis for sire $i$;

$\overline{D Y D}=$ weighted average of DYD of clinical mastitis;

$P T A_{i j}=$ PTA of trait $j$ for sire $i$;

$\overline{P T A}_{j}=$ weighted average of PTA for trait $j$;

$\hat{r}_{D Y D, P T A_{\mathrm{j}}}=$ weighted correlation between DYD for clinical mastitis and sires' PTA for trait $j$; and the other variables are as declared above.

Thus, in a simple weighted regression analysis, the standardized regression coefficient equals the weighted correlation between DYD and PTA for the various traits. This correlation can be regarded as a measure of predictive ability. Alternatively the correlation between DYD and PTA for the two traits can be estimated as the square root of the coefficient of determination. The expectation of [3] can be written:

$$
\begin{aligned}
& E\left(\hat{r}_{D Y D, P T A_{j}}\right) \\
& =E\left(\frac{\sum_{i=1}^{p}\left(w_{i}\left(D Y D_{i}-\overline{D Y D}\right)\left(P T A_{i j}-\overline{P T A}_{i}\right)\right)}{\sqrt{\sum_{i=1}^{p}\left(w_{i}\left(D Y D_{i}-\overline{D Y D}\right)^{2}\right) \sum_{i=1}^{p}\left(w_{i}\left(P T A_{i j}-\overline{P T A}\right)^{2}\right)}}\right) \\
& =\frac{\sum_{i=1}^{p} w_{i} \sigma_{T_{A, P T A}}}{\sqrt{\sum_{i=1}^{p}\left(w_{i} \sigma_{T A}^{2}+\sigma_{e}^{2}\right) \sum_{i=1}^{p} w_{i} \sigma_{P T A_{j}}^{2}}} \\
& =\frac{\sigma_{T A, P T A_{j}}}{\sqrt{\left(\sigma_{T A}^{2}+\frac{p \sigma_{e}^{2}}{\sum_{i=1}^{p} w_{i}}\right) \sigma_{P T A_{j}}^{2}}} \propto r_{T A, P T A_{j}}
\end{aligned}
$$

where

$$
\begin{aligned}
\sigma_{T A, P T A_{\mathrm{j}}}= & \text { covariance between sires' transmitting } \\
& \text { abilities for CM and sires' PTA for trait } j ;
\end{aligned}
$$

$$
\begin{aligned}
\sigma_{T A}^{2}= & \text { variance of transmitting abilities for CM; } \\
\sigma_{P T A_{\mathrm{j}}}^{2}= & \text { variance of PTA for trait } j ; \\
\sigma_{e}^{2}= & \text { residual variance of single observations } \\
& \text { for CM; } \\
r_{P T A_{\mathrm{j}} T A_{\mathrm{CM}}=} & \text { accuracy of PTA for trait } j ; \text { and the other } \\
& \text { variables are as defined above. }
\end{aligned}
$$

Hence, the expectation of the weighted correlation between DYD for CM and PTA is proportionally related to accuracy of selection. Therefore, assuming the same intensity of selection for CM and LSCS, the standardized regression coefficients from simple linear weighted regression of DYD on PTA for either of the two traits, are proportional to single trait selection response between sire and daughter in incidence of CM. These regression coefficients were therefore estimated and used to compare efficiency of selection against CM based on the two traits.

A more practical measure for efficiency of selection is the expected change in incidence of $\mathrm{CM}$ per unit intensity of selection, which equals the standard deviation of predicted DYD for CM $\left(\sigma_{P D Y D}\right)$. This was estimated by multiplying the regression coefficient in [2] by the estimated standard deviation of PTA for the corresponding trait. As second-crop daughters were not used in prediction of transmitting abilities, all sires with first-crop daughters were used to estimate standard deviations of PTA for the two traits.

\section{Improved Efficiency from Combining Information on LSCS and CM}

To examine whether predictive ability would improve from combining information on LSCS and CM relative to single-trait selection, DYD of CM in second-crop daughters was regressed on PTA in first-crop daughters of both CM and LSCS, by use of weighted multiple regression. As previously, number of second-crop daughters per sire was used as weight.

As for simple regression, the square root of coefficient of determination, being proportional to accuracy of selection, could be used to estimate predictive ability. When combining information for CM and LSCS in selection, the relative weights that should be given to standardized PTA of the two traits are the standardized regression coefficients measured in percent.

Expected change in incidence of CM per unit intensity of selection equals the standard deviation of predicted DYD for CM ( $\left.\sigma_{P D Y D}\right)$, which was estimated as:

$$
\hat{\sigma}_{P D Y D}=\sqrt{\hat{b}_{1}^{2} \hat{\sigma}_{P T A_{1}}^{2}+2 \hat{b}_{1} \hat{b}_{2} \hat{\sigma}_{P T A_{1}, P T A_{2}}+\hat{b}_{2}^{2} \hat{\sigma}_{P T A_{2}}^{2}}
$$

where $\mathrm{PTA}_{1}$ and $\mathrm{PTA}_{2}$ denotes the PTA for $\mathrm{CM}$ and LSCS, respectively. 
Table 2. Estimated regression coefficients from simple linear, weighted regression analyses of mean daughter deviations (DYD) of clinical mastitis among second-crop daughters on sires ( $p=321$ ) PTA for either; clinical mastitis (CM) or lactation mean SCS (LSCS), calculated from first-crop daughters, utilizing complete or smaller ${ }^{1}$ size of daughter groups, respectively.

\begin{tabular}{|c|c|c|c|c|}
\hline & \multicolumn{2}{|c|}{$\begin{array}{l}\text { Complete daughter } \\
\text { groups }\end{array}$} & \multicolumn{2}{|c|}{$\begin{array}{l}\text { Smaller daughter } \\
\text { groups }\end{array}$} \\
\hline & $\mathrm{CM}$ & LSCS & $\mathrm{CM}$ & LSCS \\
\hline Regression coefficients & 0.9928 & 0.1190 & 1.0080 & 0.1215 \\
\hline $\mathrm{SE}$ & 0.0708 & 0.0139 & 0.0973 & 0.0153 \\
\hline$t$ & 14.02 & 8.54 & 10.36 & 7.96 \\
\hline$P$-value ${ }^{2}$ & $<0.001$ & $<0.001$ & $<0.001$ & $<0.001$ \\
\hline Coefficient of determination & 0.3814 & 0.1861 & 0.2517 & 0.1658 \\
\hline $\mathrm{r}_{\mathrm{DYD}, \mathrm{PTA}}$ & 0.62 & 0.43 & 0.50 & 0.41 \\
\hline Expected change in CM incidence per $i(\%)^{3}$ & 2.3 & 1.5 & 1.9 & 1.4 \\
\hline
\end{tabular}

${ }^{1}$ The dataset with smaller daughter groups was created by randomly excluding approximately $50 \%$ of the herds.

${ }^{2}$ For hypothesis, $\mathrm{b}=0$.

${ }^{3} i=$ intensity of selection.

\section{Nonlinear Genetic Relationship Between CM and LSCS}

A possible nonlinear genetic relationship between CM and LSCS was tested with a quadratic weighted regression model, regressing DYD of CM among secondcrop daughters on PTA of LSCS, calculated from firstcrop daughters utilizing complete daughter groups.

\section{RESULTS}

Table 2 shows results from simple linear weighted regression analyses of DYD for CM among second-crop daughters on PTA for CM and LSCS in first-crop daughters both for full and reduced daughter group sizes, respectively. For CM, regression coefficients were not significantly different from 1 either for complete or smaller size daughter groups, implying unbiased evaluation. The regression coefficients for both traits were highly significant $(P<0.001)$ even for the smaller daughter groups. For complete daughter groups the correlation between DYD for CM and PTA for CM was 43\% larger than the corresponding correlation between DYD for CM and PTA for LSCS, implying an improved predictive ability of CM over LSCS. When selecting on $\mathrm{CM}$ and LSCS, expected change in incidence of CM per unit intensity of selection were 2.3 and $1.5 \%$, respectively. For the smaller daughter groups the correlation between DYD for CM and PTA for CM was 23\% larger than the corresponding correlation between DYD for CM and PTA for LSCS. Thus, the reduction in predictive ability due to smaller daughter groups was more pronounced for CM (19\%) than for LSCS (6\%). When selecting on CM and LSCS, expected change in CM incidence per unit intensity of selection were 1.9 and $1.4 \%$, respectively.
Results from the multiple regression analyses are shown in Table 3. The regression coefficients for the two traits were both highly significant $(P<0.001)$. For complete daughter groups the model including both traits explained $45 \%$ of the variation in incidence of clinical mastitis, slightly more than the largest value of $38 \%$ obtained for CM in simple linear regression (Table 2), improving predictive ability by $8 \%$. Expected change in CM incidence per unit intensity of selection was $2.4 \%$. For smaller daughter groups, the largest coefficients of determination were 0.25 in simple regression analysis of CM (Table 2), and 0.32 by use of multiple regression analysis (Table 3 ), corresponding to $13 \%$ increase in predictive ability. For the multiple regression analysis, expected change in CM incidence per unit selection intensity was $2.1 \%$. The standardized regression coefficients from the multiple regression model, indicated that the relative weight that should be put on relative PTA for CM and LSCS were, respectively, 67 and 33\%, for complete daughter groups and 60 and $40 \%$ for reduced daughter groups.

Figure 1 shows DYD of CM for elite sires by PTA of LSCS, based on data from all herds, with corresponding linear and quadratic regression lines. The plot for quadratic regression indicates reduced increase in $\mathrm{CM}$ for increasing PTA of LSCS. However, the quadratic term was not significant, as shown in Table 4.

\section{DISCUSSION}

Genetic improvement of mastitis resistance can be based either on direct selection on $\mathrm{CM}$ or indirect selection, using traits genetically correlated to mastitis such as SCC. The classical approach for comparison of two criteria is by use of ordinary selection index and expected additive genetic response, requiring an estimate 
Table 3. Estimated regression coefficients from multiple linear, weighted regression analyses of mean daughter deviations (DYD) of clinical mastitis among second-crop daughters on sires' $(p=321)$ PTA for both clinical mastitis (CM) and lactation mean SCS (LSCS), calculated from first-crop daughters, utilizing complete or smaller ${ }^{1}$ size of daughter groups, respectively.

\begin{tabular}{|c|c|c|c|c|}
\hline & \multicolumn{2}{|c|}{$\begin{array}{l}\text { Complete daughter } \\
\text { groups }\end{array}$} & \multicolumn{2}{|c|}{$\begin{array}{l}\text { Smaller daughter } \\
\text { groups }\end{array}$} \\
\hline & $\mathrm{CM}$ & LSCS & $\mathrm{CM}$ & LSCS \\
\hline Multiple regression coefficients & 0.8617 & 0.0742 & 0.8337 & 0.0828 \\
\hline $\mathrm{SE}$ & 0.0704 & 0.0121 & 0.0977 & 0.0145 \\
\hline Standardized regression coefficients & 0.5361 & 0.2687 & 0.4149 & 0.2775 \\
\hline$F$ & 150.03 & 37.70 & 32.55 & 72.75 \\
\hline$P$-value ${ }^{2}$ & $<0.001$ & $<0.001$ & $<0.001$ & $<0.001$ \\
\hline Coefficient of multiple determination & \multicolumn{2}{|c|}{0.45} & \multicolumn{2}{|c|}{0.32} \\
\hline $\mathrm{r}_{\mathrm{DYD}, \mathrm{PTA}}{ }^{3}$ & \multicolumn{2}{|c|}{0.67} & \multicolumn{2}{|c|}{0.57} \\
\hline Expected change in CM incidence per $i(\%)^{4}$ & \multicolumn{2}{|c|}{2.4} & \multicolumn{2}{|c|}{2.1} \\
\hline
\end{tabular}

${ }^{1}$ The dataset with smaller daughter groups was created by randomly excluding approximately $50 \%$ of the herds.

${ }^{2}$ For hypothesis, $b_{1}=0$, or $b_{2}=0$.

${ }^{3}$ Correlation between observed DYD for CM and the estimator based on PTA for CM and LSCS.

${ }^{4} i=$ intensity of selection.

of the genetic correlation between traits. In this study an alternative approach was chosen, by regressing DYD of CM, based on second-crop daughters, on PTA from univariate genetic analyses of the two traits, based on first-crop daughters. This ensures independence between mean of fixed-effect corrected observations (DYD) for CM and predictors, allowing estimation of the two traits' ability to predict incidence of $\mathrm{CM}$ in second-crop daughters, using regression. This corresponds to validating the predictive ability of future observations by correlating observed and fitted values. For unbiased evaluation models expected value of the regression coefficient of DYD for CM regressed on PTA

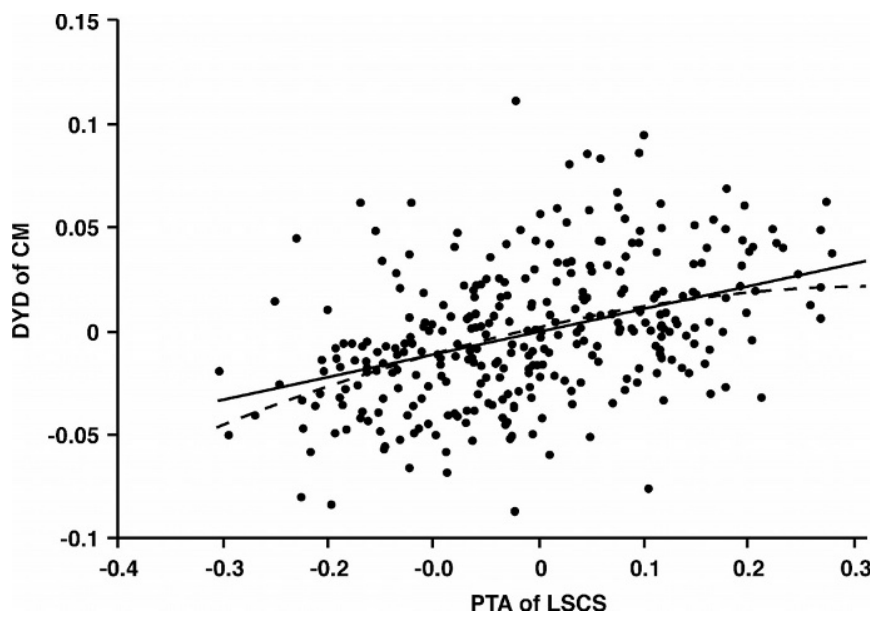

Figure 1. Plot of mean daughter deviations (DYD) of clinical mastitis (CM) among second-crop daughters by sires' ( $p=321)$ PTA of lactation mean SCS (LSCS), calculated from first-crop daughters utilizing complete daughter groups. Linear (solid line) and quadratic (dotted line) regression lines are also depicted. of $\mathrm{CM}$ equals 1 , making this an approach for validation of models used in genetic evaluation. For the purpose of comparison (CM vs. LSCS), it was necessary to standardize the regression coefficients to account for different variances of PTA for the two predictors, allowing calculation of the relative weight that should be assigned to PTA for the two traits. In the single-trait case, the resulting standardized regression coefficients equals the correlation between predictors and DYD for $\mathrm{CM}$, and were therefore proportionally related to expected selection response.

In this study, only elite sires with more than 300 second-crop daughters were included in analyses. It is known that selection may change genetic (co)variances of the selected group (Cunningham, 1975), and thereby alter the regressions. In NRF, sires are selected based on total merit index including a large number of traits. The estimated standard deviations for PTA of the two traits (CM and LSCS) were therefore only slightly reduced among elite sires compared to all sires (11 and $6 \%$, respectively). Accordingly, covariance between PTA

Table 4. Estimated regression coefficients from weighted quadratic regression analysis of mean daughter deviations (DYD) of clinical mastitis among second-crop daughters on sires' ( $p=321)$ PTA for lactation mean SCS (LSCS), calculated from first-crop daughters, utilizing complete size of daughter groups.

\begin{tabular}{lcc}
\hline & Linear & Quadratic \\
\hline Regression coefficients & 0.1129 & -0.1444 \\
SE & 0.0144 & 0.0904 \\
Standardized regression coefficients & 0.4277 & -0.0820 \\
$F$ & 69.37 & 2.55 \\
$P$-value $^{1}$ & $<0.001$ & 0.111 \\
Coefficient of multiple determination & 0.18 & \\
\hline
\end{tabular}

${ }^{1}$ For hypothesis, $b_{1}=0$, or $b_{2}=0$. 
for the two traits was also slightly reduced (8\%). This indicates that selection has only affected the results to a minor degree.

The result of the regression analyses showed that direct selection for reduced incidence of $\mathrm{CM}$ is 23 to $43 \%$ more efficient than indirect selection using LSCS, considering single-trait selection only. Hence, the higher heritability of SCC compared to CM (Mrode and Swanson, 1996) did not compensate for a genetic correlation lower than unity, even for smaller daughter groups. However, both traits are capable of changing incidence of CM in second-crop daughters. Therefore, genetic improvement of mastitis resistance is feasible through selection on LSCS, in accordance with previously reported results (McDaniel et al., 1993; Philipsson et al., 1995; Lund et al., 1994; Rogers et al., 1998; Lund et al., 1999; Nash et al., 2000; Cranford and Pearson, 2001; Kadarmideen and Pryce, 2001).

In the multiple-regression model, the individual regression coefficients for both traits were highly significant, and the coefficient of determination was slightly larger than for simple regression using CM, indicating 8 to $13 \%$ increase in efficiency from using information for both traits. This suggests that selection schemes using LSCS in addition to CM would result in a limited, but significant, increase in the accuracy of selection and thus higher selection response compared with selection schemes solely based on CM.

No significant nonlinear relationship between CM and LSCS was found $(P>0.10)$. However, the regression coefficient for the second-order term indicated reduced increase in CM for increasing PTA of LSCS, as depicted in Figure 1. This supports the relationship found by Rogers et al. (1998), regressing PTA for CM on PTA for mean SCS, and Nash et al. (2000) regressing CM and total number of CM episodes on PTA for mean SCS. To the contrary, Philipsson et al. (1995) observed no significant nonlinear relationship between EBV of mean SCS and CM. The absence of a significant quadratic relationship at low PTAs for SCS may be explained by the fact that the trait examined was an average over several SCS records, for which high values may result from low initial SCC and high subsequent values. Hence, a nonlinear relationship may be difficult to detect in analyses based on lactation mean of SCS.

\section{CONCLUSIONS}

Direct selection for reduced incidence of CM is substantially more efficient than indirect selection using LSCS, although both traits are capable of changing incidence of CM in second-crop daughters. Relative to direct selection on CM, combining the two traits in selection will slightly increase efficiency of selection. No significant nonlinear genetic relationship was found between CM and LSCS.

\section{ACKNOWLEDGMENTS}

The access to the data was given by the Norwegian Dairy Herd Recording System (Husdyrkontrollen) in agreement number 6/1998. GENO Breeding and A.I. Association is acknowledged for providing pedigree information on sires. The project has received funding from the Research Council of Norway, TINE Norwegian Dairies BA, and GENO Breeding and A.I. Association.

\section{REFERENCES}

Beaudeau, F., C. Fourichon, H. Seegers, and N. Bareille. 2001. Risk of clinical mastitis in dairy herds with a high proportion of low individual somatic-cell counts. Prev. Vet. Med. 53:43-54.

Beaudeau, F., H. Seegers, C. Fourichon, and P. Hortet. 1998. Association between milk somatic cell counts up to 400,000 cells $/ \mathrm{ml}$ and clinical mastitis in French Holstein cows. Vet. Rec. 143:685-687.

Coffey, E. M, W. E. Vinson, and R. E. Pearson. 1986. Somatic cell counts and infection rates for cows of varying somatic cell count in initial test of first lactation. J. Dairy Sci. 69:552-555.

Cranford, J. L., and R. E. Pearson. 2001. Relationships of sire predicted transmitting ability for somatic cell score with measures of daughter performance. J. Dairy Sci. 84:1501-1507.

Cunningham, E. P. 1975. Multistage index selection. Theor. Appl. Genet. 46:55-61.

Detilleux, J., P. Leroy, and D. Volckaert. 1997. Alternative use of somatic cell counts in genetic selection for mastitis resistance. Pages 34-44 in Proc. Int. Workshop on Genetic Improvement of Functional Traits in Cattle; Health. INTERBULL Bull. No. 15. Int. Bull Eval. Serv., Uppsala, Sweden.

Groeneveld, E., and M. Kovac. 1990. A generalized computing procedure for setting up and solving mixed linear models. J. Dairy Sci. 73:513-531.

Heringstad, B., G. Klemetsdal, and J. Ruane. 1999. Clinical mastitis in Norwegian cattle: Frequency, variance components, and genetic correlation with protein yield. J. Dairy Sci. 82:1325-1330.

Heringstad, B., G. Klemetsdal, and J. Ruane. 2000. Selection for mastitis resistance in dairy cattle-a review with focus on the situation in the Nordic countries. Livest. Prod. Sci. 64:95-106.

Heringstad, B., G. Klemetsdal, and J. Ruane. 2001. Selection responses for clinical mastitis in the Norwegian Cattle population. Acta Agric. Scand. Sect. A. Anim. Sci. 51:155-160.

International Bull Evaluation Service. 1996. Sire evaluation procedures for non-dairy-production and growth \& beef production traits practised in various countries 1996. INTERBULL Bull. No. 13. Int. Bull Eval. Serv., Uppsala, Sweden.

Kadarmideen, H. N., and J. E. Pryce. 2001. Genetic and economic relationships between somatic cell count and clinical mastitis and their use in selection for mastitis resistance in dairy cattle. Anim. Sci. 73:19-28.

Lund, M. S., J. Jensen, and P. H. Petersen. 1999. Estimation of genetic and phenotypic parameters for clinical mastitis, somatic cell production deviance, and protein yield in dairy cattle using Gibbs sampling. J. Dairy Sci. 82:1045-1051.

Lund, T., F. Miglior, J. C. M. Dekkers, and E. B. Burnside. 1994. Genetic relationships between clinical mastitis, somatic cell count, and udder conformation in Danish Holsteins. Livest. Prod. Sci. 39:243-251.

McDaniel, B. T., R. W. Adkinson, and M. M. Schutz. 1993. Regression of incidence of clinical mastitis on sire evaluations for somatic cell score. J. Dairy Sci. 76(Suppl. 1):238. (Abstr.)

Mrode, R. A., and G. J. T. Swanson. 1996. Genetic and statistical properties of somatic cell count and its suitability as an indirect 
means of reducing the incidence of mastitis in dairy cattle. Anim. Breed. Abstr. 64:847-857.

Nash, D. L., G. W. Rogers, J. B. Cooper, G. L. Hargrove, J. F. Keown, and L. B. Hansen. 2000. Heritability of clinical mastitis incidence and relationships with sire transmitting abilities for somatic cell score, udder type traits, productive life, and protein yield. J. Dairy Sci. 83:2350-2360.

Ødegård, J., G. Klemetsdal, and B. Heringstad. 2003. Variance components and genetic trend for somatic cell count in Norwegian Cattle. Livest. Prod. Sci. 79:135-144.

Philipsson, J., G. Ral, and B. Berglund. 1995. Somatic cell count as a selection criterion for mastitis resistance in dairy cattle. Livest. Prod. Sci. 41:195-200.

Rogers, G. W., G. Banos, U. Sander Nielsen, and J. Philipsson. 1998. Genetic correlations among somatic cell scores, productive life, and type traits from the United States and udder health measures from Denmark and Sweden. J. Dairy Sci. 81:1445-1453.

Rupp, R., and D. Boichard. 2000. Relationship of early first lactation somatic cell count with risk of subsequent first clinical mastitis. Livest. Prod. Sci. 62:169-180.
Schukken, Y. H., T. J. G. M. Lam, and H. W. Barkema. 1997. Biological basis for selection on udder health traits. Pages 27-33 in Proc. International Workshop on Genetic Improvement of Functional Traits in Cattle; Health, Uppsala, Sweden, June, INTERBULL Bull. No. 15.

Schukken, Y. H., K. E. Leslie, D. A. Barnum, B. A. Mallard, J. H. Lumsden, P. C. Dick, G. H. Vessie, and M. E. Kehrli. 1999. Experimental Staphylococcus aureus intramammary challenge in late lactation dairy cows: Quarter and cow effects determining the probability of infection. J. Dairy Sci. 82:2393-2401.

Schukken, Y. H., B. A. Mallard, J. C. M. Dekkers, K. E. Leslie, and J. Stear. 1994. Genetic impact on the risk of intramammary infection following Staphylococcus aureus challenge. J. Dairy Sci. 77:639-647.

Shuster, D. E., E. K. Lee, and M. E. Kehrli. 1996. Bacterial growth, inflammatory cytokine production, and neutrophil recruitment during coliform mastitis in cows within ten days after calving, compared with cows at midlactation. Am. J. Vet. Res. 57:15691575.

Suriyasathaporn, W., Y. H. Schukken, M. Nielen, and A. Brand. 2000. Low somatic cell count: A risk factor for subsequent clinical mastitis in a dairy herd. J. Dairy Sci. 83:1248-1255. 